"Fl suler ide mis hiipses

Año 13.

Núm. 33

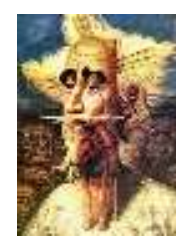

Revista de Investigación

Académica sin Frontera

ISSN: 2007-8870

\title{
http://revistainvestigacionacademicasinfrontera.com
}

Recibido el 15 de agosto de 2020. Dictaminado mediante arbitraje favorablemente 11 de diciembre de 2020.

\section{Reflexiones sobre una criminología teórica y criminología de las profesiones}

\section{Reflections on theoric criminology and professions criminology}

\author{
Wael Sarwat Hikal Carreón*
}

\section{Resumen}

En el presente artículo de reflexión, se analizan las diferencias entre las llamadas teorías de la criminalidad con las teorías criminológicas, aclarando que las primeras fueron desarrolladas por profesionales no "criminólogos" de primera carrera, sino por otros profesionales, este análisis para incitar a la creación de teorías por parte de criminólogos de formación universitaria, lo que permitirá prestigiar sus conocimientos y capacidades de construcción de la realidad, así como de utilidad implementativa. Por otro lado, se postula la consolidación de una criminología de las profesiones que de parámetros para la ética, habilidades, técnicas, conocimientos, capacidades, monopolio de ejercicio profesional y utilidad en los campos social, empresarial y público. Además de establecer estándares de calidad en la formación universitaria en los estudios de criminología. Se aborda el tema también de la pertenencia a organizaciones de profesionales para lograr objetivos de: demarcación de profesionales calificados para determinado ejercicio; establecer y mantener el nivel profesional de calidad; prácticas honorables; elevación de estatus, y reconocimiento de la profesión por los grupos sociales, empresariales y públicos. Finalmente, el objetivo es reflexionar sobre los elementos que desde la pedagogía, la investigación científica y la profesión, pueden aumentar la calidad en la formación universitaria del criminólogo, para que además, tenga

\footnotetext{
* Facultad de Filosofía y Letras, Universidad Autónoma de Nuevo León. Correo wael.hikalcrr@uanl.edu.mx. Orcid https://orcid.org/0000-0003-1278-567X
} 
"Fl suler dite mis hijisa

Año 13.

Núm. 33

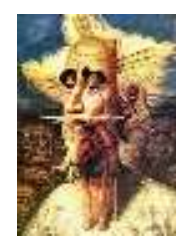

Revista de Investigación

Académica sin Frontera

ISSN: 2007-8870

\title{
http://revistainvestigacionacademicasinfrontera.com
}

Recibido el 15 de agosto de 2020. Dictaminado mediante arbitraje favorablemente 11 de diciembre de 2020.

repercusiones en el reconocimiento de este profesional, que mejore su impacto social, científico y laboral.

Palabras clave: Educación en materia criminológica; Investigación científica; Profesión del criminólogo; Teoría de la criminología.

\begin{abstract}
This article of reflection discusses the differences between so-called crime theories with criminological theories, clarifying that the former were developed by professionals not first-career "criminologists", but by other professionals, to incite the creation of theories by university-trained criminologists, which will enable them to prestige their knowledge and skills of building reality, as well as an implementive utility. On the other hand, it is postulated the consolidation of a criminology of professions that parameters for ethics, skills, techniques, knowledge, skills, monopoly of professional exercise and usefulness in the social, business and public fields. In addition to establishing quality standards in university training in criminology studies. It also addresses the issue of membership of professional organizations to achieve objectives of: demarcation of qualified professionals for a given exercise; establish and maintain the professional level of quality; honorable practices; elevation of status, and recognition of the profession by social, business and public groups. Finally, the objective is to reflect on the elements that from pedagogy, scientific research and profession, can increase the quality in the university training of the criminologist, so that it also has an impact on the recognition of this professional, which improves its social, scientific and labor impact.
\end{abstract}

Keywords: Criminological education; Criminology theory; Profession of the criminologist; Scientific research. 
"Fl silwer ile mis hijics

Año 13.

Núm. 33

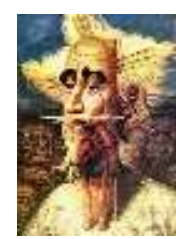

Revista de Investigación

Académica sin Frontera

ISSN: 2007-8870

\section{http://revistainvestigacionacademicasinfrontera.com}

Recibido el 15 de agosto de 2020. Dictaminado mediante arbitraje favorablemente 11 de diciembre de 2020.

\section{Introducción}

Son dos propuestas y reflexiones las que se postulan en el presente artículo, por un lado, se aborda la diferenciación entre teorías de la criminalidad con teorías criminológicas, señalando de dónde provienen unas y en dónde podrían generarse las otras para el incremento del corpus teórico de la criminología o una teoría de la criminología. En este sentido, se aprovecha el momento para tratar de disipar la distancia que existe entre teoría y práctica, procurando aclarar el porqué de considerarlas como entes apartados de la realidad, para conciliar que su unión es indispensable y que una se deriva de la otra. Por otra parte, se aborda el tema de una criminología de las profesiones para tener claridad sobre cómo podría ser la formación del criminólogo, sus campos de ejercicio, monopolio de actividad, colegiación de profesionales para empoderar su prestigio.

\section{Vicios de interpretación entre la teoría y práctica en la criminología}

Las teorías de la criminalidad se han tomado como "teorías criminológicas" emanadas de la misma criminología, esto ha sido un error, puesto que tales desarrollos provienen de profesionales como psicólogos, sociólogos, juristas, médicos, entre otros cuya formación de base o primera carrera son aquellos campos del conocimiento, no han sido criminólogos de licenciatura, si se considera que las tesis de licenciatura y posgrado pretenden ser la explicación a un problema y su probable respuesta, se queda "pendiente" el convertirse en teoría, puesto que en pocos momentos, los casos no son comprobados empíricamente, sino abordados desde una explicación mediante revisión documental.

No es el caso generalizar lo anterior, se observa tal situación en la licenciatura, en la maestría y doctorado, el contexto cambia, ocurre que en la maestría, pocas veces (el ideal es lo 
"Fl suler ide mis hiipses

Año 13.

Núm. 33

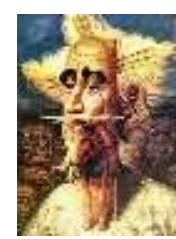

Revista de Investigación

Académica sin Frontera

ISSN: 2007-8870

\section{http://revistainvestigacionacademicasinfrontera.com}

Recibido el 15 de agosto de 2020. Dictaminado mediante arbitraje favorablemente 11 de diciembre de 2020.

contrario) logran esas tesis convertirse en artículos, capítulos en libro o libro completo, tal vez algunos proyectos de tesis logran convertirse en proyectos de implementación directa en un sector productivo y se les da continuidad. Para el doctorado, si consideramos de toda la población de licenciatura que llega hasta el doctorado, tal vez únicamente el 5\% aspira a tal grado. Se aspira a que quienes se preparan en una maestría y doctorado, serán los profesionales idóneos para investigar, sistematizar, construir la realidad, proponer nuevas alternativas, cuestionar lo que ya existe y cómo se procede ante fenómenos; es decir, poder "hacer ciencia". "La ciencia, en su continuo progreso, va ofreciendo cada vez más convincentes alternativas que contraponer a las formulaciones tradicionales" (Skinner citado en Carrasco Galán y Prieto Ursúa, 2016, p. 79).

Con esto se pretende reflexionar sobre la cantidad reducida de criminólogos de primera carrera o incluso de segunda carrera (es decir, algún abogado o sociólogo de licenciatura cuyo posgrado sea en criminología), que estén desarrollando teorías expuestas en medios idóneos para la difusión formal del conocimiento, esto para darles la etiqueta de "teorías criminológicas" y no teorías de la criminalidad mal interpretadas o inclinadas como si hubieran sido desarrolladas por "criminólogos" o emanadas de la criminología teórica. Es decir, Freud, Erikson, Maslow, Parsons, Sutherland, Lombroso, Sheldon, DiTullio, etcétera, no eran criminólogos de primera (y algunos ni de segunda carrera puesto que para algunos casos, aún no existían los estudios de criminología de manera institucionalizada).

Las teorías creadas por los autores mencionados, en su momento, explicaban la criminalidad desde ópticas biológicas, psicoanalíticas, sociológicas, humanistas, entre otras, no es que por ejemplo Durkheim estuviera construyendo una criminología sociológica, tampoco Ferri, sino que este último lo que hizo fue una sociología criminal, incluso atribuida su paternidad a esta, Freud no realizaba criminología psicoanalítica, sino psicoanálisis, posteriormente otros autores desarrollaron psicoanálisis criminal. Aquellas teorías, durante la construcción de los pilares de la criminología como educación institucional en los centros universitarios, se armó de la sociología, 
"Fl suler ide mis hiipses

Año 13.

Núm. 33

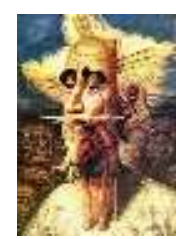

Revista de Investigación

Académica sin Frontera

ISSN: 2007-8870

\section{http://revistainvestigacionacademicasinfrontera.com}

Recibido el 15 de agosto de 2020. Dictaminado mediante arbitraje favorablemente 11 de diciembre de 2020.

psicología, psiquiatría, derecho, economía, política, antropología, por lo tanto, por ejemplo, de esta última, se tomó la teoría de Strauss, de las demás, fueron teorías sociológicas, psicológicas, jurídicas, entre otras, que desde su posición, expliquen el fenómeno, esto resultó en una criminología con miradas a lo antisocial, violencia, delito, psicopatía, sociopatía, etcétera.

El valor de mercado de las teorías logró tal poder que permearon las enseñanzas universitarias de la criminología en casi todas las regiones de América (incluso las mismas desarrolladas en Estados Unidos de América en la escuela de Chicago u otras). Pero, si buscamos teoría natural desarrollada por criminólogos de primera carrera, se ve poco o nada, si buscáramos alguna teoría criminológica creada por un mexicano o colombiano, o peruano o de otra región, queda muy invisibilizado, por otro lado ¿Quién no ha leído a Sutherland (EUA)? Se debe tener claro que una teoría de la criminalidad no es lo mismo que una teoría criminológica, estas últimas serán las desplegadas por "criminólogos" de formación, estamos en la época en la que ya existen los licenciados en criminología, y no la atribución de títulos como en los filósofos griegos según sus aportaciones.

Por otro lado, en este sentido, debemos generar nuestra propia teoría quienes somos criminólogos de primera (licenciatura), segunda (maestría) o tercer carrera (doctorado), reiterando que en esta época tenemos profesiones que se encuentran delimitadas por un campo de acción, o un monopolio (Freidson, 2001), de tal manera, el corpus teórico crecerá, teniendo diversidad de propuestas de solución e implementación ante diversas expresiones de la criminalidad por regiones, países, contextos, tiempos, aprendiendo de otras localidades, programas, experiencias comparadas, etcétera, a lo que comúnmente, exportamos teorías de Europa, EUA, Asia u otros sitios. Es momento de elaborar una teoría de la criminología.

La sociedad actual, dice Skinner, se halla en una situación de crisis y no parece que haya motivo para dudar de la verdad de dicha afirmación; baste considerar algunos de los problemas que más nos desconciertan: la intolerancia racial y religiosa, la violencia, la amenaza de una guerra nuclear, la sobrepoblación, la 
"Fl suler ide mis hiipses

Año 13.

Núm. 33

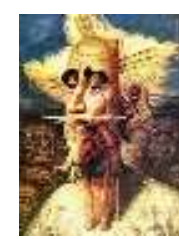

Revista de Investigación

Académica sin Frontera

ISSN: 2007-8870

\section{http://revistainvestigacionacademicasinfrontera.com}

Recibido el 15 de agosto de 2020. Dictaminado mediante arbitraje favorablemente 11 de diciembre de 2020.

contaminación, el agotamiento de recursos, la pobreza generalizada, la drogadicción y la brecha generacional (Skinner citado por Bowen, J. y Hobson, 2001, p. 266).

La criminología latinoamericana a través del desarrollo de sus teorías (en proceso), comenzará a cumplir su cometido original cuando abandone el modelo de limitarse a meramente adoptar de manera autocomplaciente las teorías de otros campos del conocimiento y de otros países, ha vivido en un autoaislamiento y limitación impuesta por sus profesionales, se quedó en una ignorancia teórica (Carr, 2002), desplazada por la impaciencia de la generación actual por establecer una práctica que por hoy se estanca en procedimientos que sí dan atención a la inmediatez, pero no a la reflexión histórica, ni a la detección de conductas divergentes y de riesgo para prevenirlas, no debemos limitarnos a intervenir sobre los hechos ya cotidianos, sino visualizar las nuevas apariciones para explicarlas y abordarlas.

Otro problema que debemos afrontar es la "distancia” entre la teoría y práctica, las cuales su significación no es explícita sino que deben desmenuzarse para poderlas unir, interpretar e implementar (Freidson, 2001), con ello, podemos animar y ampliar el conocimiento sobre la naturaleza de estas, de lo cual, cotidianamente se tienen manifiestos débiles y concepciones erróneas de lo que en la actualidad se considera "teoría" y "práctica", que se contamina por interpretaciones populares no profesionales, pero que incluso estos mismos las toman como lenguaje cotidiano. La teoría es la que aporta los recursos para interpretar la realidad y funcionan como una guía para trabajarla y reconstruirla. Opuesto a ello "se considera que el teórico hace sus aportaciones desde la biblioteca, el laboratorio, la mesa de trabajo o el estrado, mientras que el práctico las hace en la interacción directa (...)” (Kemmis, 2002, p. 33).

Algunos profesionales ven la práctica o la teoría desde fuera, como entidades aisladas y no como unidades, la teoría no es especulación, que es con lo que de inicio se interpreta, como un conjunto de pensamientos que los autores idealizan o fabrican en su imaginación (Comte, 1999) basada en sus percepciones y a partir de las cuales, en la especulación se cree se puede explicar lo 
"Fl suler ide mis hiipses

Año 13.

Núm. 33

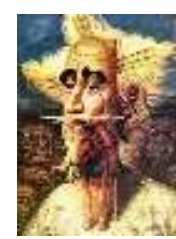

Revista de Investigación

Académica sin Frontera

ISSN: 2007-8870

\section{http://revistainvestigacionacademicasinfrontera.com}

Recibido el 15 de agosto de 2020. Dictaminado mediante arbitraje favorablemente 11 de diciembre de 2020.

"otro" o lo que nos rodea, esto es especular, mientras que la teoría, es el caso de campo (físico, documental, videográfico, fotográfico, musical, histórico o cualquier otro que sea objeto de estudio), que mediante métodos de instrumentación del estudio, recolección de información, experimentación e interpretación de resultados, se ha probado o descartado.

¿Qué ocurre para considerar que la práctica está lejos de la teoría? Desde el punto de vista aquí expuesto, se explicaría por la individualización de la que se desarrolla la teoría sobre "casos particulares", si leemos una teoría sobre la población, esta puede ser sobre alguna en particular, no es la misma teoría de la población la que explica la comunidad en Nueva York, que en Estado de México, si leemos teoría antropológica de los criminales italianos, no va a explicar la de los criminales en Bolivia, si observamos el Global Peace Index 2020 (Institute for Economics \& Peace, 2020) de los países menos pacíficos están Siria, Venezuela, Iraq, Palestina, Israel, México, Afganistán, Colombia ¿Se podría explicar con la teoría que explique la violencia en Venezuela la de Siria? ¿ ¿Con la teoría de Palestina a México? La respuesta podría ser que "no”, por la diversidad en cultura, idioma, desarrollo histórico, etcétera, incluso, la comida, música, no son similares ni aproximadas.

Estos ejemplos sirven para tratar de disipar que existen teorías generales que expliquen el todo, pensemos en la teoría de las ventanas rotas que fue aplicada en California y Nueva York, si la queremos implementar en el municipio de San Nicolás De Los Garza en Nuevo León, o en Acapulco De Juárez, Guerrero, ambos en México, pero en polos del territorio mexicano ¿Aplicaría el mismo procedimiento? Se vuelve a que la respuesta podría ser "no", pero lo que sí se puede hacer es generalizar el conocimiento y buscar que los procedimientos se reajusten al contexto específico (Carr, 2002), por tanto se aplica una teoría tropicalizada al particular y se genera una nueva explicación o incluso una teoría fundamentada. Cabe aclarar también, que un libro no es una teoría (aunque podría ser una tesis), un capítulo en libro, un artículo, tampoco son una teoría, salvo que así lo indique como un escrito basado en "investigación", identificado por partes como: 
"Fl suler ide mis hiipses

Año 13.

Núm. 33

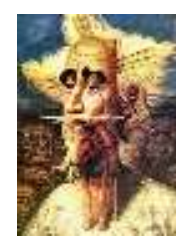

Revista de Investigación

Académica sin Frontera

ISSN: 2007-8870

\section{http://revistainvestigacionacademicasinfrontera.com}

Recibido el 15 de agosto de 2020. Dictaminado mediante arbitraje favorablemente 11 de diciembre de 2020.

Introducción, población, método, resultados, conclusiones, cuando se refiere a especulaciones, pueden llevar la etiqueta de escrito de "reflexión".

Con lo anterior, se propone estimular a la reflexión de hasta dónde estamos anclados en el pensamiento científico, donde separamos o distanciamos la teoría de la práctica, las miramos como dos opuestos que no hayan momento de encuentro o una inútil para la otra (Kemmis, 2002). Una teoría busca ser capaz de ver lo que no está explícito, descubrir, probar o refutar lo que se especula mediante cuestionamientos sobre lo que se duda o quiere resolver, seleccionar una población muestra, aplicar métodos de medición, recolección, explicar los resultados y llegar a conclusiones. La ciencia se distingue de Dios porque para este, los resultados y explicaciones son un misterio, mientras que para la ciencia, sus efectos son claros y evidentes. De ese modo, la criminología debe dar resultados al servicio de la sociedad o empresas (beneficiarios) y de la política (toma de decisiones, financiadores de los proyectos), basada en los problemas locales o mundiales.

Con la madurez de la criminología a nivel global, se fueron acumulando más estudios de otras ciencias (colección de saberes) que también explican el fenómeno de la criminalidad vista desde la sociología, psicología, antropología, estadística, política, filosofía, etcétera, en algunas universidades, investigadores particulares, organismos no gubernamentales u otros, han avanzado a la especialización (criminologías específicas), pasando de por ejemplo, una sociología criminal a una criminología sociológica, o una psicología criminal a una criminología psicológica, entre otras, también surgieron congresos específicos en materia de criminología, revistas, libros, salidas profesionales, se consolidaron estudios universitarios de pre y posgrado, sociedades académicas, colegios de profesionales, lo que hila a una criminología de las profesiones. 
"Fl silwer ile mis hijics

Año 13.

Núm. 33

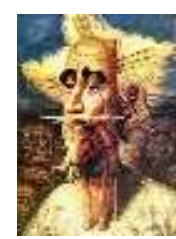

Revista de Investigación

Académica sin Frontera

ISSN: 2007-8870

\section{http://revistainvestigacionacademicasinfrontera.com}

Recibido el 15 de agosto de 2020. Dictaminado mediante arbitraje favorablemente 11 de diciembre de 2020.

\section{Una teoría de las profesiones para la criminología}

Los estudios de criminología se profesionalizaron en las instituciones de educación superior para atender a la explicación de los problemas de la criminalidad, entendiéndola, pero también atendiendo al campo del bienestar social (para prevenir). A la vez, el criminólogo debe ser agradable a los intereses de la industria, del gobierno y de la sociedad, de tal modo logrará aceptación e involucramiento en las primeras dos áreas para ejercer su práctica profesional, y en la sociedad, para que esta perciba los resultados que este profesional brinda. Con dicha profesionalización, los criminólogos (su función es saber del tema específico) institucionalizan sus funciones en actuación de un marco social con necesidades particulares, de ese modo se diferencian de otros profesionales. Ríos Patio (2017) puntualiza el concepto de “criminólogo" de la siguiente manera:

El criminólogo es un profesional que estudia las causas, factores, condiciones y motivos que generan criminalidad. Su labor es de suyo trascendental porque la cuestión criminal confronta el nivel de seguridad integral del Estado, el cual está íntimamente vinculado al bienestar general, ya que son conceptos interdependientes y complementarios, que apuntan a la aspiración de la organización social toda hacia el bien común (2017, p. 16).

Además, conociendo las causas generadoras de conductas lesivas y evitándolas, se interviene en las relaciones intersubjetivas de intereses, zona de donde emergen los conflictos, de manera previa y positiva, no extemporánea ni negativa, esto es, reaccionando y castigando (2017, p. 17).

Para que el "prestigio" de un criminólogo eche raíces, debe mostrar su capacidad para resolver problemas sociales, su práctica determinará el valor de sus habilidades. Existen fronteras difusas entre lo que hace un criminólogo de primera carrera (licenciatura) a con un sociólogo 
"Fl suler ide mis hiipses

Año 13.

Núm. 33

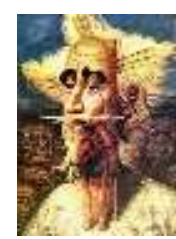

Revista de Investigación

Académica sin Frontera

ISSN: 2007-8870

\section{http://revistainvestigacionacademicasinfrontera.com}

Recibido el 15 de agosto de 2020. Dictaminado mediante arbitraje favorablemente 11 de diciembre de 2020.

dedicado a lo criminal, igual con un psicólogo, abogado, trabajador social, etcétera, la misma acumulación de conocimientos por parte de la criminología de todas estas profesiones, no permitió una claridad sobre sus campos específicos de acción (Freidson, 2001); es decir ¿En qué se diferencia un criminólogo de un abogado penalista? Pero al revés, si hay más claridad profesional por parte de un abogado general o especializado, e igual en otros profesionales. La antropología, psicología y sociología nacen casi a la par que la criminología, pero estas tres, han logrado establecer campos concretos de estudio y actuar, la criminología, aún no del todo.

La criminología de las profesiones debe estudiar y proponer sobre la delimitación del criminólogo en su campo laboral (Hikal Carreón, 2020d), salidas profesionales esclareciendo acciones, su jurisdicción profesional, identidad (Hikal Carreón, 2020c), formación educativa, estructura organizativa, vinculación con estructuras de poder, estatus, actualización frecuente, autonomía científica y profesional, y actividad profesional, (Fernández Pérez, 2001), vigilará su actuar mediante una forma controlada derivada de la formación, ello ayudará "a que los alumnos obtengan conocimientos, habilidades, actitudes, valores culturales y éticos, contenidos en un perfil profesional y que corresponde a los requerimientos para un determinado ejercicio" (Fernández Pérez, 2001, p. 28).

Cuando la profesión del criminólogo se instauró en la Universidad Autónoma de Nuevo León (UANL) se postularon salidas profesionales y actividad relacionadas a lo penitenciario, seguridad pública, privada, investigaciones, peritajes (en los planes de estudios mixtos entre criminología-criminalística). Pronto surgieron sociedades académicas, algunos colegios, más centros escolares (Hikal Carreón, 2020a). La profesión se establece como un medio de vida, determinado por un ingreso, monopoliza una serie de actividades, desempeñando con legalidad actos que otro no podría realizar, por ejemplo, el ejercicio de la medicina no lo ejerce otro profesional, la abogacía la ejecuta el profesional legalmente habilitado para tal efecto (Fernández Pérez, 2001). No un criminólogo-médico, ni un criminólogo-abogado, contrario a ello, para ejercer 
"Fl suler ide mis hiipses

Año 13.

Núm. 33

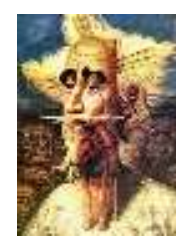

Revista de Investigación

Académica sin Frontera

ISSN: 2007-8870

\section{http://revistainvestigacionacademicasinfrontera.com}

Recibido el 15 de agosto de 2020. Dictaminado mediante arbitraje favorablemente 11 de diciembre de 2020.

la criminología si la puede realizar un filósofo, pedagogo, médico, entre otros, por ello la importancia de marcar esos límites hoy que ya existen los criminólogos de licenciatura.

Por parte de los colegios de profesionales de la criminología, deben trabajar para que definan un perfil profesional, ética, buenas prácticas, reglamentación, sanciones y aboguen también por el monopolio de su competencia (Freidson, 2001) o la ampliación del mercado de trabajo donde puedan ser empleados o una labor multiprofesional, y por hacer profesionales genuinos. “Asimismo, los profesionistas constituyen asociaciones profesionales con la finalidad de definir criterios de admisión, niveles educativos, títulos o exámenes de ingreso, carreras y áreas de jurisdicción” (Fernández Pérez, 2001, p. 26). Parkin (citado en Fernández Pérez, 2001, p. 26) sugiere "estrategias de exclusión para restringir el acceso a las profesiones utilizando requisitos educativos (...)", "el Estado da el derecho a practicar ciertas ocupaciones a miembros acreditados" (Fernández Pérez, 2001, p. 26); es decir, se legaliza el oficio profesional, acreditado mediante una cédula y título.

Para el caso de México, existen tantos organismos no gubernamentales (ONGs) (Hikal Carreón, 2020b) que tienen en su función a la criminología y criminalística, de los cuales, una gran mayoría se ocupa de la capacitación, y certificaciones falsas; es decir, a estos organismos no les acreditan organizaciones superiores que en su añejamiento y trabajo, descanse su respaldo, para ello, el criminólogo que busque certificarse, deberá hacerlo en las instituciones acreditadas para ello, y si en su labor está el investigar, este debe investigar bien a la organización donde se someterá a certificación, apartándose de falsas horas de valor curricular, diplomados no avalados por las secretarías de educación, entre otras falacias. Por el contrario, los colegios deben defender los derechos de los profesionales, entre sus asociados, procurarán sus intereses, aportando ideas, propuestas, acciones, hacerse escuchar para mejoras y soluciones a problemas determinados, de ese modo, su estatus como profesional, aumenta (Fernández Pérez, 2001), pero no a través del morbo, cursos de los crímenes de moda o fomentando el fanatismo, puesto que ello, no corresponde 
"Fl suler ite mis hijica

Año 13.

Núm. 33

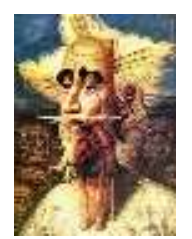

Revista de Investigación

Académica sin Frontera

ISSN: 2007-8870

\section{http://revistainvestigacionacademicasinfrontera.com}

Recibido el 15 de agosto de 2020. Dictaminado mediante arbitraje favorablemente 11 de diciembre de 2020.

a la responsabilidad profesional, desafortunadamente, los dirigentes de muchas ONGs en la materia, son laxos defensores, más que de sus propios intereses, prestigio y beneficio propio.

En términos generales, las asociaciones profesionales en México no definen el cuerpo básico de conocimientos de su campo que tendría que ser enseñado en las instituciones de educación superior, no establecen propuestas normativas para la profesión, tampoco regulan el ingreso a ella, no moderan las iniciativas personales ni facilitan la búsqueda de empleo; en términos generales, estas agrupaciones solamente ofrecen oportunidades para la expresión social, obtener un cierto prestigio, adquisición de material documental, participación en seminarios o reuniones ocasionalmente (Fernández Pérez, 2001, p. $33)$.

Los colegios o asociaciones de profesionales deben abogar por los siguientes principios (Fernández Pérez, 2001; Freidson, 2001):

- Demarcar a los profesionales calificados y certificados;

- Establecer y mantener el nivel profesional;

- Prácticas honorables;

- Elevación de estatus, y

- Reconocimiento de la profesión por los grupos sociales, empresariales y públicos.

Nos encontramos en un momento en el que mucho podemos hacer por dignificar la profesión del criminólogo en México y el resto de América, trabajar en una serie de teorías de la profesión aplicadas a la criminología, permitirá lograr los objetivos antes expuestos, para empoderar a este profesional, así como explicitar sus capacidades y conocimientos a través de resultados efectivos para atender los graves problemas que aquejan a la sociedad por la violencia, 
"Fl suler ite mis hijics

Año 13.

Núm. 33

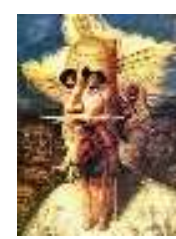

Revista de Investigación

Académica sin Frontera

ISSN: 2007-8870

\section{http://revistainvestigacionacademicasinfrontera.com}

Recibido el 15 de agosto de 2020. Dictaminado mediante arbitraje favorablemente 11 de diciembre de 2020.

criminalidad y antisocialidad, violaciones de derechos humanos, desigualdad, entre otros. También el reforzar a las agrupaciones colegiadas para establecer la reglamentación de este profesional, su actuar y sus actividades profesionales.

\section{Conclusiones}

Es necesario aclarar la diferencia entre teorías de la criminalidad y teorías criminológicas, para delimitar el desarrollo de ciertos profesionales y establecer lo que las nuevas generaciones pueden elaborar para construir una teoría de la criminología. Los problemas de credibilidad a la teoría resultan de querer aplicar procedimientos probados en otros contextos, diferencias de métodos de recogida de datos, resultados, etcétera, se resolverá efectuando modificaciones adaptándose a las nuevas circunstancias para lograr el resultado deseado. Por otro lado, el establecer una criminología de las profesiones que permita dar claridad a la profesionalización de la carrera en criminología, delimitando campos de estudio, ejercicio, acción, ética, habilidades, conocimientos e identidad profesional.

\section{Lista de referencias}

Bowen, J. y Hobson, P.R. (2001). Teorías de la Educación. Innovaciones Importantes en el Pensamiento Educativo Occidental. Ciudad de México: Editorial Limusa.

Carr, W. (2002). Una Teoría para la Educación. Hacía una Investigación Educativa Crítica. Madrid: $\quad$ Ediciones $\quad$ Morata. $\quad$ Recuperado https://rfdvcatedra.files.wordpress.com/2019/02/carr-2002-una-teoria-para-la-educacionhacia-una-investigacion-educativa-critica-pdf.pdf 
"Fl suleer ile mis hiipses

Año 13.

Núm. 33

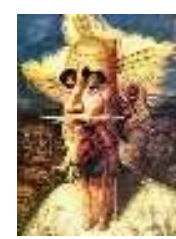

Revista de Investigación

Académica sin Frontera

ISSN: 2007-8870

\section{http://revistainvestigacionacademicasinfrontera.com}

Recibido el 15 de agosto de 2020. Dictaminado mediante arbitraje favorablemente 11 de diciembre de 2020.

Carrasco Galán, M.J. y Prieto Ursúa, M. (2016). Skinner, contribuciones del conductismo a la educación. Revista Padres y Maestros, (367), 77-80. Recuperado de https://revistas.comillas.edu/index.php/padresymaestros/article/view/7129

Comte (1999). Discurso sobre el Espíritu Positivo. Discurso Preliminar del Tratado Filosófico de Astronomía Popular. Madrid: Editorial Biblioteca Nueva.

Fernández Pérez, J.A. (2001). Elementos que consolidan el concepto profesión. Notas para su reflexión. REDIE. Revista Electrónica de Investigación Educativa, 3(2). Recuperado de https://www.redalyc.org/articulo.oa?id=15503202\&iCveNum=225

Freidson, E. (2001). La teoría de las profesiones. Estado del arte. Perfiles Educativos, 23(93). Recuperado de http://www.scielo.org.mx/pdf/peredu/v23n93/v23n93a3.pdf

Hikal Carreón, W.S. (2020a). Censo de centros escolares y programas educativos en criminología, criminalística, victimología y carreras afines en México. Archivos de Criminología, Seguridad Privada y Criminalística, 8(15), 154-182. Recuperado de https://dialnet.unirioja.es/servlet/articulo?codigo=7497236

Hikal Carreón, W.S. (2020b). Censo de organismos no gubernamentales en materia criminal en México. Archivos de Criminología, Seguridad Privada y Criminalística, 8(15), 183-200. Recuperado de https://dialnet.unirioja.es/servlet/articulo?codigo=7497236

Hikal Carreón, W.S. (2020c). Construcción de la identidad profesional del criminólogo y criminalista en México. E-Eguzkilore. Revista Electrónica de Ciencias Criminológicas, 5 , $1-33$. Recuperado de https://ojs.ehu.eus/index.php/eguzkilore/article/view/21830/19650

Hikal Carreón, W.S. (2020d). Empleabilidad para el criminólogo y criminalista en México. El Criminalista Digital. Papeles de Criminología, (2)8, 51-70. Recuperado de http://150.214.104.41/crimdig/08hikal.pdf 
"Fl suler ile mis hiips

Año 13.

Núm. 33
Revista de Investigación

Académica sin Frontera

ISSN: 2007-8870

\section{http://revistainvestigacionacademicasinfrontera.com}

Recibido el 15 de agosto de 2020. Dictaminado mediante arbitraje favorablemente 11 de diciembre de 2020.

Institute for Economics \& Peace (2020). Global Peace Index 2020: Measuring Peace in a Complex

World. Sydney: Institute for Economics \& Peace. Recuperado de http://visionofhumanity.org/app/uploads/2020/06/GPI_2020_web.pdf

Kemmis, S. (2002). La teoría de la práctica educativa. En Carr (ed.). Una Teoría para la Educación. Hacía una Investigación Educativa Crítica. Madrid: Ediciones Morata. Recuperado de https://rfdvcatedra.files.wordpress.com/2019/02/carr-2002-una-teoria-para-la-educacionhacia-una-investigacion-educativa-critica-pdf.pdf

Ríos Patio, G. (2017). "El criminólogo en la empresa". A propósito del nuevo modelo de prevención criminal introducido por la Ley $\mathrm{N}^{\circ} 30424$ modificada por el Decreto Legislativo $\mathrm{N}^{\circ}$ 1352. Instituto de Investigación Jurídica. 1-21. http://www.repositorioacademico.usmp.edu.pe/bitstream/handle/usmp/2675/rios_pg16;js essionid=4FF0D8F0923D203A05420BCD5D88B620? sequence $=1$ 
"Fl siler ite mis hijisa

Año 13.

Núm. 33
Revista de Investigación

Académica sin Frontera

ISSN: 2007-8870

http://revistainvestigacionacademicasinfrontera.com

Recibido el 15 de agosto de 2020. Dictaminado mediante arbitraje favorablemente 11 de diciembre de 2020.

\section{Directorio Institucional}

Dr. Enrique Fernando Velázquez Contreras

Rector

Dr. Ramón Enrique Robles Zepeda

Secretario General Académico

Dra. Rosa María Montesinos Cisneros

Secretaria General Administrativa

Dr. Rodolfo Basurto Álvarez

Director de Vinculación y Difusión

Dra. Adriana Leticia Navarro Verdugo

Vicerrectora de la Unidad Regional Sur

Dr. Ernesto Clark Valenzuela

Director de la División de Ciencias Económicas y Sociales

Dr. Francisco Espinoza Morales

Secretario de la División de Ciencias Económico y Sociales

Dra. Leticia María González Velásquez

Jefe del Departamento de Ciencias Económico Administrativas

Dra. Lidia Amalia Zallas Esquer

Jefe de Departamento de Ciencias Sociales 
"Fl suler ide mis hiipses

Año 13.

Núm. 33

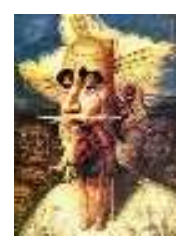

Revista de Investigación

Académica sin Frontera

ISSN: 2007-8870

\section{http://revistainvestigacionacademicasinfrontera.com}

Recibido el 15 de agosto de 2020. Dictaminado mediante arbitraje favorablemente 11 de diciembre de 2020.

\section{Comité Directivo}

\section{Editor Responsable}

Dr. Francisco Espinoza Morales

Universidad de Sonora

Directora

Dra. Leticia María González Velásquez

Universidad de Sonora

Subdirector

Dr. Javier Carreón Guillen

Universidad Nacional Autónoma de México

Editor Científico

Dr. Cruz García Lirios

Universidad Autónoma del estado de México

Master Gráfico

M.T.I. Francisco Alan Espinoza Zallas

Universidad Estatal de Sonora

Nos complace anunciar que su diario, "Academic Research Journal Withoutborders" (ISSN/EISSN 20078870) fue evaluado positivamente en la indexación Citefactor, ahora la página de la revista está disponible en línea, en caso de cualquier problema.

Journals Master | International Innovative Journal Impact Factor (IIJIF)

\section{Red Latinoamericana de revistas Académicas en Ciencias Sociales y Humanidades}
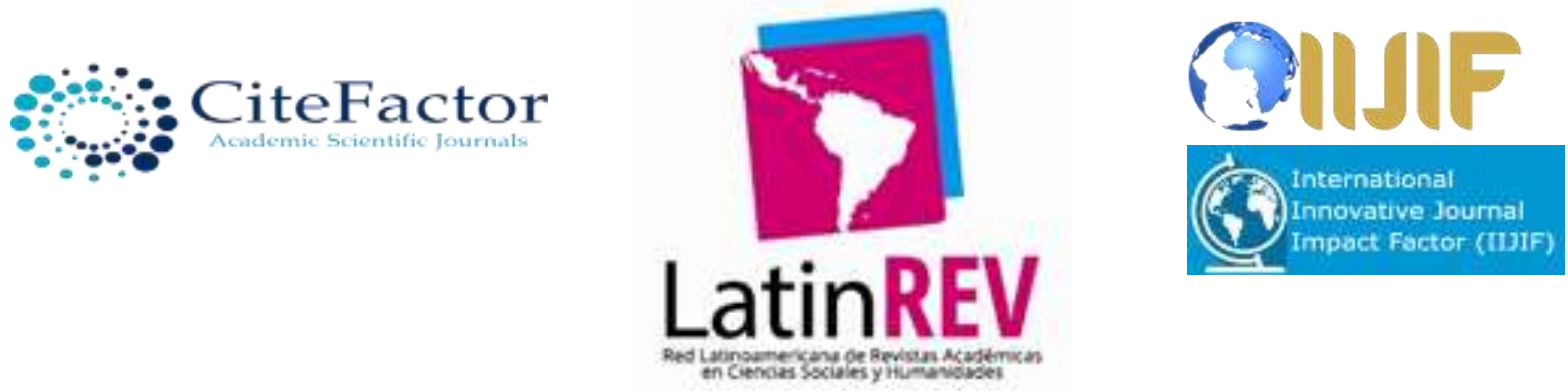
"Fl sibler ite mis hijise

Año 13.

Núm. 33
Revista de Investigación

Académica sin Frontera

ISSN: 2007-8870

\section{http://revistainvestigacionacademicasinfrontera.com}

Recibido el 15 de agosto de 2020. Dictaminado mediante arbitraje favorablemente 11 de diciembre de 2020.

\section{Comité editorial}

Dra. Angélica María Rascón Larios

Universidad de Sonora. México

Dra. María del Rosario Molina González

Universidad de Sonora

Dra. Francisca Elena Rochin Wong

Universidad de Sonora. México

Dra. Lidia Amalia Zallas Esquer

Universidad de Sonora. México

Dra. Beatriz Llamas Arechiga

Universidad de Sonora. México

Dr. Rogelio Barba Álvarez

Universidad de Guadalajara. México

Dra. Rosa María Rincón Ornelas

Universidad de Sonora. México

Dr. Juan Flores Preciado

Universidad de Colima. México

Dr. Amado Olivares Leal. Universidad de Sonora

Universidad de Sonora. México

Dr. Guillermo Velázquez Valadez.

Instituto Politécnico Nacional (IPN) México

Dr. Hugo Nefstalí Padilla Torres.

Universidad Estatal de Sonora. México

Dr. Luis Ramón Moreno Moreno.

Universidad Autónoma de Baja California. México

Dr. Miguel Ángel Vázquez Ruiz.

Universidad de Sonora. México

Dra. Lorena Vélez García. 
"Fl silwer ise mis hijics

Año 13.

Núm. 33
Revista de Investigación

Académica sin Frontera

ISSN: 2007-8870

\section{http://revistainvestigacionacademicasinfrontera.com}

Recibido el 15 de agosto de 2020. Dictaminado mediante arbitraje favorablemente 11 de diciembre de 2020.

Universidad Autónoma de Baja California. México

Dra. Pabla Peralta Miranda.

Universidad Simón Bolívar, Barranquilla, Colombia

Mtro. Roberto Espíritu Olmos

Universidad de Colima (FCA Tecomán) Colima

Dr. Héctor Priego Huertas.

Universidad de Colima (FCA Tecomán) Colima

Mtra. María Guadalupe Alvarado Ibarra.

Universidad de Sonora. México.

MSc. Celso Germán Sánchez Zayas

Universidad de Camagüey, Ignacio Agramonte Loynaz, Cuba

Dra. María Luisa Quintero Soto

Universidad Autónoma del Estado de México

Dr. Eyder Bolivar Mojica

Universidad Católica, Luis Amigó, Medellin, Colombia

Revisores de Textos en Inglés

Mtro. Renato Encinas

Mtra. Cecilia Guadalupe Martínez Solano

\section{Comité científico}

Dr. Rosendo Martínez Jiménez. Universidad Autónoma Benito Juárez de Oaxaca.

Dr. Hugo Neftalí Padilla. Universidad Estatal de Sonora

Dra. María Teresa Gaxiola Sánchez. Universidad de Sonora.

Dr. José Cesar Kaplan. Universidad Estatal de Sonora.

Dr. Alfredo Islas Rodríguez. Universidad de Sonora

Frecuencia de publicación: semestral / 2 números por año. 


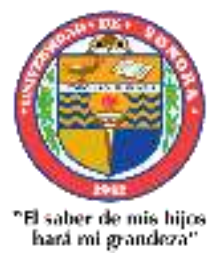

Año 13.

Núm. 33
( Julio - Diciembre 2020)

Revista de Investigación

Académica sin Frontera

ISSN: 2007-8870

\section{http://revistainvestigacionacademicasinfrontera.com}

Recibido el 15 de agosto de 2020. Dictaminado mediante arbitraje favorablemente 11 de diciembre de 2020.

Revista de Investigación Académica sin Frontera (RIASF) con (ISSN: 2007-8870) es un interlocutor internacional de acceso abierto revisado diario en línea en el ámbito del de las Ciencias Económicas Administrativas y Sociales. Su objetivo principal es dar a los trabajos de investigación de calidad. Cubre todas las sub-campos de los campos anteriormente mencionados. Proporciona la plataforma a académicos, estudiantes y profesionales. Sólo pública trabajos de investigación y artículos de revisión inicial. Documento presentado debe cumplir con algunos criterios como, debe ser original, inédita y no estén sometidos a ninguna otra revista.

RIASF es una revista arbitrada / Revisión por pares International. Publicamos documentos sobre una variedad de temas, contextos y estrategias de análisis que examinan la relación entre la rápida evolución para la Sociedad y la tecnología del conocimiento.

REVISTA DE INVESTIGACIÓN ACADÉMICA SIN FRONTERA, Año 13, No. 33, Julio - diciembre 2020, es una publicación semestral de investigación científica, editada por la Universidad de Sonora, a través de las División de Ciencias Económicas y Sociales, de la Unidad Regional Sur, Blvd. Lázaro Cárdenas No. 100, Col. Francisco Villa, Navojoa, Sonora, Sonora, México, C.P. 85880. Tel. (642) 425- 99-54. http://www.revistainvestigacionacademicasinfrontera.com/, revistaacademicasinfrontera@ unison.mx.

Editor responsable: Francisco Espinoza Morales. Reserva de Derechos al Uso Exclusivo: 04-2013121811323700-203 e ISSN: 2007-8870, ambos otorgados por el Instituto Nacional de Derecho de Autor. Inscrita en el Directorio de LATINDEX, con Núm. De folio 20014, folio único 14590. Responsable de la última actualización de este Número, Unidad Informática de la Universidad de Sonora, fecha de la última modificación, 30 de diciembre 2020, indexada a Cite Factor Academic Scientific Journal y Journals Master (IIJIF) y Red Latinoamericana de Revistas Académicas en Ciencias Sociales y Humanidades, (Latín Rev). Las opiniones expresadas por los autores no necesariamente reflejan la postura del editor de la publicación. Se autoriza la reproducción total o parcial de los contenidos e imágenes en la presente publicación siempre y cuando se cuente con la autorización del editor y se cite plenamente la fuente. 
"Fl suler ide mis hiipses

Año 13.

Núm. 33

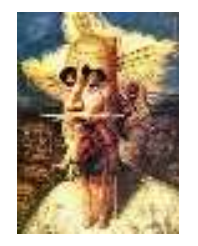

Revista de Investigación

Académica sin Frontera

ISSN: 2007-8870

\section{http://revistainvestigacionacademicasinfrontera.com}

Recibido el 15 de agosto de 2020. Dictaminado mediante arbitraje favorablemente 11 de diciembre de 2020.

Nos complace anunciar que su diario, "Academic Research Journal Withoutborders" (ISSN/EISSN 20078870) fue evaluado positivamente en la indexación Citefactor, ahora la página de la revista está disponible en línea, en caso de cualquier problema.

Journals Master | International Innovative Journal Impact Factor (IIJIF)

\section{Red Latinoamericana de revistas Académicas en Ciencias Sociales y Humanidades}
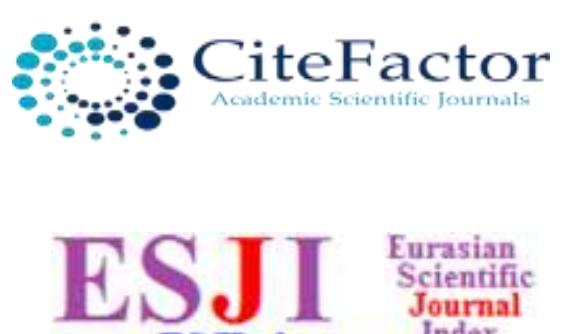

Eurasian Scientific Journal www.ESJIndex.org

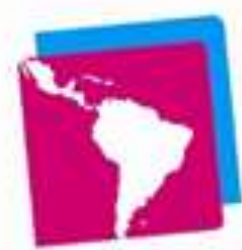

LatinREV

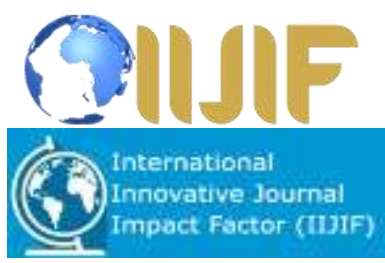

https://www.neliti.com
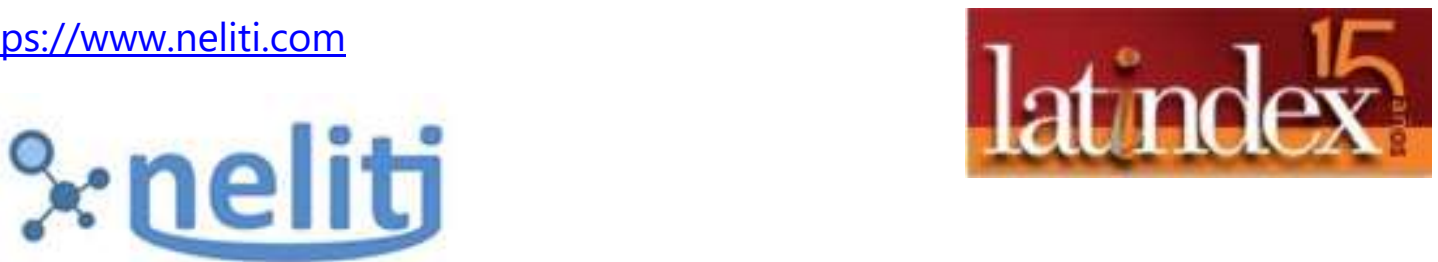

Indonesia's Research Repository

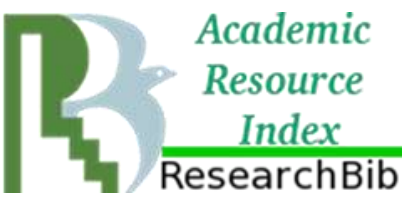

